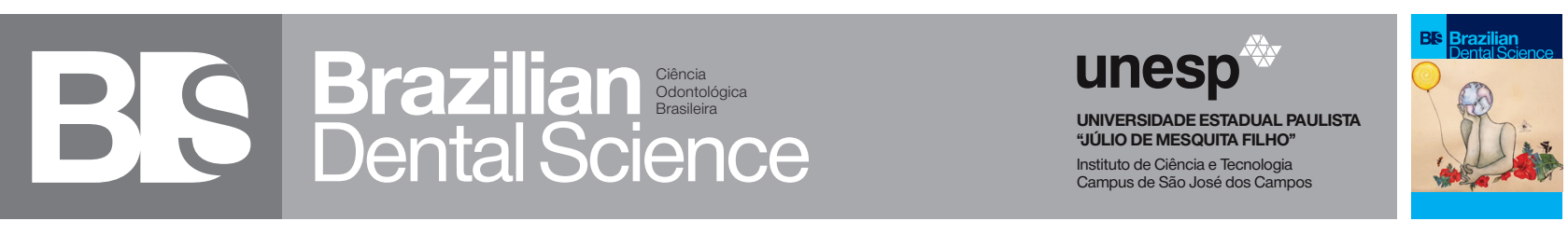

\title{
Nanostructured platelet-rich plasma: state of art in dental treatments
}

\author{
Plasma-rico em plaquetas nanoestruturado: estado da arte nos tratamentos dentais
}

Gabriela DURÁN ${ }^{1}$, Angela C.M. LUZO ${ }^{2}$, Wagner J. FÁVARO ${ }^{1}$, Nelson DURÁN ${ }^{1,3}$

1 - Laboratory of Urogenital Carcinogenesis and Immunotherapy - Department of Structural and Functional Biology - University of Campinas (UNICAMP) - Campinas - SP - Brazil.

2 - Public Umbilical Cord Blood Bank - Haematology Hemotherapy Center/INCT do Sangue - University of Campinas (UNICAMP) Campinas -Brazil.

3 - Nanomedicine Research Unit (Nanomed) - Center for Natural and Human Sciences (CCNH) - Federal University of ABC (UFABC) -Santo André - Brazil.

\begin{abstract}
Objectives: Reviewing information available about platelet-rich plasma (PRP) applied to dental treatments, introducing the general concept of PRP, as well as analyzing actual data about, and challenges faced by, the dental field. Data \& sources: The current study analyzed the most informative publications about PRP application available in this field and gathered the maximum information about it as possible. Conclusions: PRP use, either alone or in association with other biomaterials, can significantly favor different fields such as tissue engineering, since it is an innovative technique that attracts the interest of clinicians and basic scientists. However, it is necessary conducting better designed and controlled experiments to enable successful tissue healing based on PRP use. Clinical significance: The current review can be used by clinicians as source of information about the actual rules and protocols adopted in the herein addressed field, besides providing specific examples of such applications.
\end{abstract}

\section{KEYWORDS}

Platelet-rich plasma; Dental treatment; Plateletgrowth factors; Nanotechnology; Bone regeneration; Surgery.

\section{RESUMO}

Objetivos: Revisar as informações disponíveis sobre o plasma-rico em plaquetas (PRP) aplicado a tratamentos odontológicos, introduzir o conceito geral de PRP e analisar dados reais sobre os desafios enfrentados pelo campo odontológico. Dados e fontes: O presente estudo analisou as publicações mais informativas sobre a aplicação do PRP disponíveis neste campo e reuniu o máximo de informações possível. Conclusões: O uso do PRP, isoladamente ou em associação com outros biomateriais, pode favorecer significativamente diferentes campos, como a engenharia de tecidos, uma vez que é uma técnica inovadora que atrai o interesse de clínicos e cientistas básicos. No entanto, é necessário realizar experimentos mais bem projetados e controlados para permitir a cura bem-sucedida dos tecidos com base no uso do PRP. Significado clínico: A revisão atual pode ser usada pelos médicos como fonte de informações sobre as regras e protocolos atuais adotados no campo aqui tratado, além de fornecer exemplos específicos de tais aplicações.

\section{PALAVRAS-CHAVE}

Plasma-rico em plaquetas; Tratamento dental; Fatores de crescimento plaquetar; Nanotecnologia; Regeneração de tecidos; Cirurgia. 


\section{INTRODUCTION}

$\mathrm{T}$ he aims of the current review were to synthesize information available about platelet-rich plasma (PRP) application in dental treatment, in order to introduce the general concept of PRP, as well as to analyze the actual data about, and challenges faced by, this field. Specific information about the actual rules of the herein investigated application was addressed to be used by clinicians. Another important point lies on PRP definition as a nanostructured protein, given the nanometric scale of these particles. It is essential emphasizing that nanotechnology is an important topic in dentistry [1,2]. The description of nanostructures based on dynamic light scattering has shown the contributions from exosome-nanoparticles (diameter smaller than $50 \mathrm{~nm}$ ), nanoparticles (diameter ranging from 50 to $550 \mathrm{~nm}$ ), platelet/nano-aggregates (diameter bigger than $550 \mathrm{~nm}$ ) [3-7]. Special considerations were dedicated to nanometric PRP-exosomes [8,9].

The current review was an attempt to approach the most informative publications in the herein investigated field; however, it did not intend to exhaust all dentistry-related topics.

\section{WHAT IS PLATELET- RICH PLASMA (PRP)?}

\section{General aspects}

Platelets are cell fragments (approximate diameter $=2 \mu \mathrm{m}$ ) of megakaryocytes produced in the bone marrow [10,11]. They have large amounts of bioactive proteins that play a key role in tissue healing or hemostasis [12]. Basic proteingrowth factors (GFs) are essential for wound healing processes; as well as blood proteins such as fibronectin, fibrin and vitronectin, which are known as cell adherence molecules $[13,14]$.

The activation process (degranulation) releases granules found in platelets in order to merge to the cell membrane. During this degranulation process, the released factors [1518] are converted into a bioactive state, due to histone association, as well as into carbohydrate side chains [12]. These factors bind to transmembrane receptors of dammed tissue cells in order to trigger tissue repair and regeneration [15,19-21].

\section{PRP components: Exosomes}

Exosomes are another important topic to be taken into consideration in dental field. According to Torreggiani et al. [22], exosomes are nanosized vesicles released by platelets in the extracellular compartment, as well as one of platelet lysate (PL) activity effectors. Exosomes were isolated from human PRP to enable PL activity, based on the ultracentrifugation technique. The proliferation and migration of bone marrow stromal cells (MSC) treated with exosomes have shown significant dose-dependent increase in the above processes in comparison to the control. Exosome protein content analysis has shown significant amount of VEGF (vascular endothelial growth factor), bFGF (basic fibroblast growth factor), PDGF-BB (platelet-derived growth factor) and TGF- $\beta 1$ (transforming growth factor beta 1) than in PL. The aforementioned authors suggested that exosomes have strongly contributed to PL activity and that they likely have a useful nanostructured delivery system for cell-free regeneration processes.

Alternative approaches deriving from advancements in nano-engineering have demonstrated that exosomes can also be applied to specific tissues, a fact that makes them an attractive option for targeted therapy $[8,9,23,24]$ with excellent possibilities to be used in dental pulp regeneration. A recent review reported that exosomes appeared to be a promising alternative to cell therapy focused on treating dental pulp pain and inflammation, as well as to induce pulp regeneration. Nevertheless, benefits deriving from exosome use strongly depend on recipient cells, which could be an issue in patients presenting necrotic dental pulp or in the ones subjected to pulpectomy [25].

Comments: Platelets are the first cell fragments to get to damaged tissues where they attach to the exposed collagen via Von 
Willebrand factor in order to promote platelet myofibril contraction via arachidonic acid. This process leads to platelet aggregation, which, in its turn, leads to the degranulation of alpha granules. Growth factors are released into the blood stream, through which they reach the compromised cells. They often act in the microenvironment and, depending on the growth factors stimulus and situation; they can also enable immunomodulation, tissue regeneration, neoangiogenesis and even apoptosis. According to Gawaz and Vogel [26], HGF, SDF1, IGF, TNF Alpha, BDGF, Factor H, IL 10, 4,8, 13 and 17, CXCR4, CD40L, Interferon alpha, TRAIL TWEK LIGHT, PDGF, TGF- $\beta 1$, VEGF, (bFGF) and EGF are the growth factors, interleukins and cytokines often released by platelets. PRP components such as exosomes, appear to be important to PL activity; in the near future, they may be an interesting nanodelivery structure to be used in treatments based on cell-free regeneration processes.

\section{PRP PREPARATION PROTOCOL}

As previously mentioned, PRP preparation is of paramount importance to assure reproducible results and safe applications of it. Thus, it is important describing the actual status of these preparations. Although PRP has been known for a long time, the terminology used to describe it remains confusing due to significant variation in published protocols focused on PRP normalization and preparation. In other words, many articles in this field lack a precise characterization of the assayed products. Therefore, Dhurat and Sukesh [17] reviewed the principles and PRP preparation methods grounded on accessible reports; they presented their perspective to normalize a safe and simple protocol focused on enabling optimized and consistent platelet outputs.

A mini review has analyzed and addressed the high potential of PRP to be used for tissue regeneration and considered it a reliable and efficient technique [27]. A methodical review of PRP preparation and composition protocols applied in clinical tests focused on treating musculoskeletal illness from 2006 to 2016 was conducted. It was possible concluding that a specific, accurate and step-by-step description of the PRP preparation protocol is necessary to allow comparisons between reports and affording reproducibility [28].

Etulain et al. [29] reported protocol optimization based on angiogenic PRP analysis and recuperative properties. In several cases, PRP is obtained by using commercial equipment that lack normalized preparation procedures and coherent PRP quality. Hamid [30] explored a simple and economical PRP preparation method that was useful for clinical applications. PRP was obtained based on a typical centrifugation technique. Another method known as t-PRP (temperature controlled PRP), which is free of exogenous additions, was reported. The aforementioned authors suggested that t-PRP was a new and suitable technique for PRP elaboration and stimulation without any extra addition [31].

The biology behind PRP preparation protocols and the science-based evidence applications of different platelet concentrates in several dentistry uses were reviewed [32]. Similar review was reported for wound regeneration therapies, with especial emphasis on PRP and on the important role played by GFs in wound healing processes. This therapeutic formulation involves PRGF supernatant often used in surgeries and on dental implant surfaces [18].

All these considerations must be followed by dentists who use PRP in any dental application.

Comments: It is necessary setting a step-bystep description of the PRP elaboration protocol in order to get high-quality PRP, as well as an evident standardization to allow a confrontation between reports and allow reproducibility. Moreover, controlled experiments comprising adequate samples should be conducted to test PRP effectiveness in wound healing or in any other application.

The biology behind PRP preparation protocols and science-based evidence applications of different platelet concentrates in different dentistry uses were pointed out [32]. 


\section{WHAT DO WE KNOW ABOUT PRP APPLICATIONS?}

Carlson and Roach [33] reviewed previous scientific reports about wound healing mechanisms triggered by GFs found in PRP concentrates. However, studies focused on investigating PRP applications in the dentistry field have found that PRP was efficient in enhancing surgical data in many maxillofacial surgery processes, a fact that brings hope to periodontal recuperative therapies.

The most important aspect of autologous PRP lies on eliminating concerns about immunogenic effects and disease transmission. However, properly controlled studies, mainly about oral and periodontal therapy, were suggested by the aforementioned authors [34].

In 2006, Shashikiran et al. [35] suggested that PRP appeared to have all the necessary ingredients to assure successful pediatric oral surgery procedures. Interestingly, based on their experiments, they believe that it is possible using PRP to increase bone healing after surgical cyst enucleation in children.

At this stage, interesting aspects appeared in PRP applications in comparison to the PRP preparation procedure. However, double centrifugation was effective in its application, but this induced changes in PRP ultrastructure [36].

According to Nikolidakis and Jansen [37], although GFs and their implicated mechanisms were poorly understood around 2000's, the simple PRP application during clinical procedures could lead to satisfactory results. Researchers found proof of PRP's beneficial effects on periodontal defect treatments. However, weak evidence of beneficial PRP effect on sinus lift was reported [38].

A study review has shown that the standardization of protocols and clinical trials can help better understanding PRP and plateletderived growth factor (PDGFs) contribution to sinus lift procedures $[39,40]$. Publications in 2012 about the use of several PRP types in bone grafts, implant processes and reconstructive surgeries appeared to especially productive in this period [41]. Although PRP is easily produced, it presents low potential risk and is relatively easy to be used; therefore, it is necessary conducting further randomized controlled trials (URCTs) to support the low potential risk evidence $[42,43]$.

A review conducted by Zollino et al. [44] addressed PRP effectiveness in oral surgeries and medical applications. Other studies addressed PRP uses, as well as platelet concentration effects on, and preparation in, the dentistry field [45-47].

Vineet [48] summarized all positive effects of PRP recorded in the dentistry field. Bansal et al., [49] reported excellent results in implant surgeries, in which PRP was applied as covering material. They also compared PRF to PRP use. The aforementioned authors suggested that slow polymerization during centrifugation, ease of preparation; fibrin-based structure and minimal costs make PRF rather superior than PRP at some point.

Recent reports have given proofs that PRP therapy is a promising treatment for musculoskeletal lesions and neural feedback pathways around dental implants [50]. Some comments of actual interest in PRP applications were made by Singh et al. [51]. They pointed out that PRP preparation and management normalization remains a challenge due to several parameters. However, they also stated that PRP offers many advantages to orthopaedic and maxillofacial surgeries, as well as to dental implantology and periodontology. The positive point about PRPs lies on the fact that they comprise different GFs and cytokines necessary to enable hemostasis, and that they are able to heal both soft tissues and bones.

A study focused on evaluating PRP use in bone healing after maxillofacial cyst (dental cyst extraction) extirpation was reviewed. Bone reconstruction in individuals subjected to PRP treatment was faster than that of the control group. Data collected in this study have indicated that PRP use enabled faster and superior bone reconstruction after maxillofacial cyst extraction [52]. 
Based on clinical outcomes reported for PRF, PRP and blood clot (BC) revascularization (BCR), it is possible stating that these therapies presented similar effectiveness in premature and permanent teeth regeneration [53].

Although it was not directly associated with dental PRP application, a study review addressed PRP application in dermatological therapies such as tissue regeneration, scar revision and wound healing (used in maxillofacial surgery and possibly applied to dental treatment) [54].

Comments: PRP use, either alone or in association with other biomaterials, can significantly favor different fields such as tissue engineering, since it is an innovative technique that attracts the interest of clinicians and basic scientists. However, it is necessary conducting better designed and controlled experiments to enable successful tissue healing after PRP use in dental treatment.

\section{PRP APPLICATION IN DENTISTRY}

Given the diversity of reviews about different topics addressed in dentistry [18-21], the current review deals with studies on different dental stages, which are scarce in the literature.

\section{Cells cultures}

Commercial PRP (GLO-PRP) has been used as complement to several regenerative dental techniques. Kobayashi et al. [55] studied PRP characterization in vitro and its effect on PDL (periodontal ligament) cells, human gingival fibroblasts and osteoblast cell behavior. The outcomes have demonstrated that PRP induced proliferation, gingival fibroblast migration and expression of mRNA pro-wound healing molecules. Although PRP promoted PDL cell proliferation and osteoblast migration, almost no osteoblast differentiation was observed.

Based on the analysis of PRP effect on culture media used to enhance osteogenic PLSCs (periodontal ligament stem cells) and DPSCs (dental pulp stem cells) differentiation, PRP has enhanced the osteogenic differentiation of stem cells by modulating molecular pathways in order to stimulate bone formation [56].

A research focused on evaluating PRP effect on the behavior of hGFs (human gingival fibroblasts) collected from healthy patients' peripheral blood has shown that culture medium added with 5\% PRP was the controlling option that stimulated hGFs' wound healing properties, due to its rapid and efficient impact on cell/ colony proliferation and migration [57].

Comments: PRP had selective effect on fibroblasts and PDL cells. Stimulated gingival fibroblast migration and proliferation, as well as mRNA expression in pro-wound healing molecules, were observed; however, although PRP induced PDL cells, osteoblast migration and proliferation, they did not enable osteoblast differentiation. Similar effect was observed on PLSCs and DPSCs. Efficient healing was also observed.

\section{Animal models}

A report on the effect of PRP was based on histological and histometric evaluation of the bone repair procedure applied to the core areas of extraction sockets in monkeys belonging to species Cebus apella 90 days after extraction; the control group in this study presented reduced osteogenesis signs due to bone generation procedure and fibroblast-like cell proliferation [58].

PRP use, either in combination with BioOss ${ }^{\circledR}$ (bovine inorganic bone - Geistlich) or with Bio-Gran ${ }^{\circledR}$ bioactive glass (Orthovita, Implant Innovations), was not efficient in bone healing based on the experimental conditions described in a study conducted with dogs. The authors of the aforementioned study have suggested that further investigation should be conducted to clearly define PRP effects on individuals subjected to bone repair treatments [59].

A study focused on analyzing DPSCs (dental pulp stem cells) and PRP ability to rehabilitate dental pulp in mature permanent teeth of dogs did not find improvement in fresh tissue formation when it was compared to tissue generated by BC only in root canals [60]. 
A study aimed at analyzing PRP use, either alone or in association with DPCs, in premature canine teeth with apical periodontitis, has demonstrated that PRP groups generated more tissues in root canals. DPC groups presented significantly higher mineralized tissue production in the root canal than no-DPC groups, mainly in the apical third. The PRP/DPC group recorded significant growth of bone-like tissue in the canal space in the periapical tissue [61].

A study focused on analyzing the effect of WPLTs (washed platelets) and PRP on the regeneration and mineralization of dental pulp cells in rats has found that either WPLTs or PRP were equally capable of promoting the calcification and proliferation of dental pulp cells in rats in a dose-dependent manner [62]. It is essential highlighting that this experiment adopted a physical approach (liquid nitrogen freeze-thawing) and that the biological safety of WPLTs was likely higher than that of PRP. Probably, this condition let to the recorded results, although there were no differences due to WPLTs and PRP behavior.

Since PRP administration (autologous) at the rat tooth extraction site is the most important risk factor for therapy or MRONJ (medicationrelated osteonecrosis of the jaw), several senile rats were systematically medicated with (Vehicle: $0.45 \mathrm{~mL}$ of $0.9 \%$ sodium chloride solution (VEH) and VEH-PRP. Data collected from the local application of PRP (autologous) have shown that it enabled a feasible preventive treatment; moreover, it prevented the incidence of MRONJ after tooth extraction [63].

Comments: The bone repair process based on PRP presence at the midpoint of extraction sockets in adult male monkeys presented reduced osteogenesis signs after PRP application. Bovine inorganic bone associated with PRP in dogs did not have significant effect on bone healing under the adopted experimental conditions. The DPCs/PRP system showed significant bone-like tissue growth in the canal space of the periapical tissue and enhanced vital tissue production in the root canals of premature teeth with apical periodontitis. It was clear that PRP quality was not the standard, since random results were found in different or similar animals.

\section{Human patients}

Buffy Coat-PRP (BufC-PRP) presented bone healing effect after the extraction of bilateral mandibular third molars from human patients [64]. Data indicated that this material could be useful to clinicians at the time to carry out oral surgeries, since it favors bone rehabilitation after tooth extraction.

Based on flow cytometry cell classification, PDL (human periodontal ligament) and dental pulp cells presented mesenchymal stem cell populations. There was enhancement at $1 \%$ PRP dose in the colony-forming ability, as well as cellular proliferation of dental stem cells. The real-time quantitative PCR measurement has shown increased osteogenic and odontogenic gene expressions in both PRP-processed cells PRP [40].

Implantations in the posterior region and/ or bilaterally symmetric to the median line in human patients' maxilla subjected to PRP therapy have shown that the presence, or absence of PRP in the implant sockets and implant stability quotient (ISQ) did not show significant clinical outcome. However, data demonstrated significant differences between ISQ values of PRP and nonPRP implants on the operation day [65].

A non-smoker healthy female (20 years) diagnosed with localized aggressive periodontitis was subjected to biomaterial (cement) application and to bone tissue regeneration stimulant. Next, she underwent flap surgery with bone allograft and PRP. After 1 year follow-up based on monitoring, she was classified low relapse risk for this periodontal disease [66].

Submucosal PRP injection is a method developed to increase orthodontic tooth movement by mimicking the effects of bone injury after surgery and alveolar bone loss in human patients. PRP administration on en masse anterior retraction (pressure side) diminished alveolar bone loss by approximately $75 \%$; the 
process was dose dependent [67].

A study conducted with healthy children has compared the proliferation and distinctness between stem cells from SHEDs (human exfoliated deciduous teeth) cultivated in modified platelet-rich plasma (mPRP) and the ones containing fetal bovine serum (FBS) in order to investigate an optimal mPRP dose to be used for SHEDs preservation purposes. The authors of the aforementioned study found that mPRP could effectively favor SHEDs proliferation/ differentiation, and that $2 \%$ of mPRP was able to replace 10\% FBS under SHEDs expansion and differentiation at clinical manufacturing scale [68].

Isaia et al. [69] suggested that the combination between PRP and anorganic bovine bone $(\mathrm{ABB})$ in human patients would enable prospective values for alveolar bone ridge preservation similar to that observed by Vance et al. [70]. PRP-based revascularization treatment applied to premature teeth with apical periodontitis in healthy patients has shown that PRP can act as a successful platform for regenerative endodontic therapy [71].

Evaluation of PRP effect on newly osseointegration and secondary stability values has shown higher implant stability in the primary osseointegration phase of the PRP group. However, both groups presented similar stability at the final stage of the experimental period [72].

Jalaluddin et al. [73] conducted a randomized controlled study focused on comparing PRP and bone graph use in intrabony periodontal defects. They found that both groups presented promising results in increasing periodontal regeneration, although bone graft results were better than PRP results. However, combinations between both groups were not investigated to assess synergistic possibilities.

Comments: Data have shown that PRP was valuable to dental surgeons since it favored regeneration after tooth extraction, enhanced human dental cell proliferation (PDLSCs and DPSCs). A significant difference between ISQ values of presence and absence of PRP implants on the operation day. Implant stability values were expressive in the primary osseointegration phase based on PRP use.

\section{GUIDELINES ON PRP USES}

Significant PRP use enabled clinical dentistry professionals to better understand the regulatory role played by, and importance of, PRP in American Agencies such as FDA (Food and Drug Administration). PRP is a blood product that falls into the prevue of FDA's Center for Biologics Evaluation and Research (CBER). The rules and regulatory procedures associated with these classes of products were taken into account in Code Regulations (FDA's 21 CFR 1271). PRP was exempted from these regulations and did not comply with the traditional regulatory rules set by FDA for animal experiments and clinical assays. The application named $510(\mathrm{k})$ was the way used to introduce PRP in the market. However, clinicians can use off-label products or materials as long as they accept full responsibility for it. At this point, CBER must be taken into consideration in medical practices; moreover, clinicians must accept the its responsible use and be aware of it - its use must be centered on strong scientific rationale and on solid medical facts. However, FDA does not regulate or control activated PRP. On the contrary, it suggests that clinicians working with activated PRP should be aware of these issues and concerns, and keep themselves well-informed about it $[74,75]$.

An important guideline was prepared for Alberta licensed physicians (College of Physicians and Surgeons of Alberta-CPSA) who offer and fulfill PRP services. Based on this guideline, the PRP therapy lies on the use of patients' own blood factors to improve tissue repair and healing. The PRP procedure covers multiple steps, which demand manipulating blood products; therefore, extremely attention should be paid on sustaining technique sterility and on assuring safe product use in patients. Although the processing and administration of autologous blood products is seen as a low risk activity for patients, an extra step is required to avoid blood product mislabeling or misidentification [76]. 
Comments: FDA's regulatory function and attitude on PRP are important factors; however, because it is a blood product, it can fall under the prevue of FDA's CBER through Code Regulations (FDA's 21 CFR 1271) - PRP was exempt from this regulatory pathway. An important guideline was prepared by CPSA for professionals who offer and fulfill PRP services; it pointed out a critical point, i.e., variability in different PRP aspects. This guideline states that the most critical part of PRP uses lies on professional's ability to perform all steps of PRP procedures without contamination.

\section{FINAL REMARKS AND PERSPECTIVES}

Platelets are the first cells arriving at the tissue damage site and they are specifically active in the early inflammatory stages of healing processes. They have effects on degranulation, since PDGF, TGF- $\beta 1$, VEGF, (bFGF), and EGF are mainly released from $\alpha$-granules. PRP preparation protocols are of fundamental importance, since PRP use in association with stem cells (as endogenous morphogens) and bio-scaffolds remain a research object in the regenerative endodontic field due to recent promising results in periodontal tissue regeneration.

PRP is certainly an important tool to be used in tissue engineering, as well as an innovative field for clinicians and basic researchers. However, it is necessary conducting better designed and controlled experiments to enable successful tissuehealing based on PRP use. PRP components such as exosomes appeared as an emerging topic with excellent applications. The overall conclusion is that PRP shows promising results in humans, since it increases periodontal regeneration and decreases alveolar bone loss. Important are the guidelines of PRP uses and the FDA regulatory role and attitude on PRP. The 510(k) application is recommended for PRP systems when it reaches the market. An important guideline was prepared by CPSA for professionals who offer and fulfill PRP services This guideline states that the most critical part of PRP application lies on professionals' ability to perform all steps of the PRP procedures without contamination.

\section{Acknowledgement}

Supports from FAPESP, $\mathrm{CNPq}$ and from Brazilian Network on Nanotoxicology (CIGENANOTOX) (MCTI/CNPq) are acknowledged.

\section{REFERENCES}

1. Padovani GC, Feitosa VP,Sauro S, Tay FR, Durán G, Paula AJ, et al. Advances in dental materials through nanotechnology: facts, perspectives and toxicological aspects. Trends Biotechnol. 2015 Nov;33(11):621-36. doi:10.1016/j. tibtech.2015.09.005.

2. Noronha VT, Paula AJ,Durán G, Galembeck A, Cogo-Müller K, Franz-Montan M, etal. Silver nanoparticles in dentistry. Dent Mater.2017 0ct;33(10):1110-26. doi:10.1016/j.dental.2017.07.002. Epub2017 Aug 2.

3. Maurer-SpurejE, Labrie A, Pittendreigh C,Chipperfield K, Smith C, Heddle $\mathrm{N}$, et al. Platelet quality measured with dynamic light scattering correlates with transfusion outcome in hematologic malignancies. Transfusion. 2009 Nov;49(11):2276-84. doi: 10.1111/j.1537-2995.2009.02302x.

4. Maurer-SpurejE,Larsen R, Labrie A, Heaton A, Chipperfield K. Microparticle content of platelet concentrates is predicted by donor microparticles and is altered by production methods and stress. Transfus Apher Sci. 2016 Aug;55(1):35-43. doi: 101016/j.transci.2016.07.010

5. Xu Y,Nakane N, Maurer-Spurej E. Novel test for microparticles in platelet-rich plasma and platelet concentrates using dynamic light scattering. Transfusion. 2011Feb;51(2):363-70. doi:10.1111/j.1537-2995.2010.02819.x

6. Maurer-SpurejE,Chipperfield K. Could microparticles be the universal quality indicator for platelet viability and function? J Blood Transfus.2016;2016:6140239. doi:101155/2016/6140239. Epub2016 Dec 8.

7. Millar D, Murphy L, Labrie A, Maurer-SpurejE. Routine screening method for microparticles in platelet transfusions. J Vis Exp. 2018 Jan 31;(131). doi:10.3791/56893.

8. Guo SC, Tao SC, Yin WJ, Qi X, Yuan T,Zhang CQ. Exosomes derived from platelet-rich plasma promote the re-epithelization of chronic cutaneous wounds via activation of YAP in a diabetic rat model. Theranostics. 2017 Jan 1;7(1):81-96. doi: 10.7150/thno.16803. eCollection 2017.

9. Tao SC, Yuan T, Rui BY,Zhu ZZ, Guo SC, Zhang CQ. Exosomes derived from human platelet-rich plasma prevent apoptosis induced by glucocorticoidassociated endoplasmic reticulum stress in rat osteonecrosis of the femoral head via the Akt/Bad/Bcl-2 signal pathway. Theranostics. 2017 Jan 15;7(3):733-750. doi: 10.7150/thno.17450. eCollection 2017

10. Conley CL, Hemostasis. In: Mountcastle VB, editor. Medical Physiology. St.Louis: Mosby Company;2004. p.1137-46.

11. Harrison P,Cramer EM. Platelet alpha-granules. Blood Rev. 1993 Mar;7(1):52-62. Review.

12. Schilephake H. Bone growth factors in maxillofacial skeletal reconstruction. Int J Oral Maxillofac Surg. 2002 0ct;31(5):469-84.

13. Sunitha Raja V, Munirathnam NaiduE. Platelet-rich fibrin: evolution of a second-generation platelet concentrate. Indian J Dent Res. 2008 JanMar;19(1):42-6. Review

14. Cole BJ, Seroyer ST, Filardo G, Bajaj S, Fortier LA. Platelet-rich plasma: where are we now and where are we going? Sports Health. 2010 May;2(3:203-10. 
15. Kevy SV, Jacobson MS. Comparison of methods for point of care preparation of autologous platelet gel. J Extra Corpor Technol. 2004 Mar;36(1):28-35

16. Anitua E, Sanchez M, Nurden AT,Zalduendo M, de la Fuente M, Orive G, et al Autologous fibrin matrices: a potential source of biological mediators that modulate tendon cell activities. JBiomed Mater Res A. 2006 May;77(2):285-93.

17. DhuratR, Sukesh M. Principles and methods of preparation of platelet-rich plasma: a review and author's perspective. J Cutan Aesthet Surg. 2014 OctDec;7(4):189-97. doi:10.4103/0974-2077.150734. Review

18. Chicharro-Alcántara D, Rubio-Zaragoza M,Damiá-GiménezE, Carrillo-Poveda JM, Cuervo-Serrato B, Peláez-Gorrea P, et al. Platelet rich plasma: new insights for cutaneous wound healing management. J Funct Biomater. 2018 Jan 18;9(1). pii:E10. doi:10.3390/jfb9010010.

19. Marx RE. Platelet-rich plasma: evidence to support its use. JOral Maxillofac Surg. 2004 Apr;62(4):489-96. Review

20. Antoniades HN, Williams LT. Human platelet-derived growth factor: structure and function. Fed Proc. 1983 Jun;42(9):2630-4.

21. Marx RE. Platelet-rich plasma (PRP): what is PRP and what is not PRP? Implant Dent. 2001;10(4):225-8

22. Torreggiani E, PerutF,Roncuzzi L, Zini N, Baglio SR, Baldini N. Exosomes: novel effectors of human platelet lysate activity. Eur Cell Mater.2014 Sep 22;28:13751; discussion 151

23. Gomari H,Forouzandeh Moghadam M, Soleimani M. Targeted cancer therapy using engineered exosome as a natural drug delivery vehicle. Onco Targets Ther.2018 Sep 12:11:5753-5762. doi: 10.2147/0TT.S173110. eCollection 2018.

24. Tian T,Zhang HX, He CP,Fan S, Zhu YL, Qi C, et al. Surface functionalized exosomes as targeted drug delivery vehicles for cerebral ischemia therapy. Biomaterials. 2018 Jan;150:137-149. doi: 10.1016/j.biomaterials.2017.10.012. Epub 20170 ct 4.

25. Schuh CMAP,Benso B, Aguayo S. Potential novel strategies for the treatment of dental pulp-derived pain: pharmacological approaches and beyond. Front Pharmacol. 2019 Sep 18;10:1068. doi: 10.3389/fphar.2019.01068. eCollection 2019.

26. Gawaz M, Vogel S. Platelets in tissue repair: control of apoptosis and interactions with regenerative cells. Blood. 20130ct 10;122(15):2550-4. doi: 10.1182/blood-2013-05-468694. Epub2013 Aug 20.

27. da Costa PA, SantosP.Platelet-rich plasma: a review of its therapeutic use, Braz J Clin Anal (RBAC) 2016; 48:311-19. doi: 10.21877/2448-3877.201600177

28. Chahla J, Cinque ME, Piuzzi NS, Mannava S, Geeslin AG, Murray IR, etal. A call for standardization in platelet-rich plasma preparation protocols and composition reporting: a systematic review of the clinical orthopaedic literature. J Bone Joint Surg Am. 2017 0ct 18;99(20):1769-1779. doi: 10.2106/ JBJS.16.01374

29. Etulain J,Mena HA, Meiss RP,Frechtel G, Gutt S, Negrotto S, et al. An optimised protocol for platelet-rich plasma preparation to improve its angiogenic and regenerative properties. SciRep. 2018 Jan 24;8(1):1513. doi:10.1038/s41598018-19419-6

30. Hamid MSA. CostEffectiveness of a platelet-rich plasma preparation technique for clinical use. Wounds. 2018 Jul;30(7):186-190.

31. Du L,Miao Y,LiX, Shi P,HuZ. A Novel and convenient method for the preparation and activation of PRP without any additives: temperature controlled PRP.Biomed Res Int. 2018 May 13;2018:1761865. doi: 10.1155/2018/1761865. eCollection2018

32. Ezzatt OM. Autologous platelet concentrate preparations in dentistry. Biomed J Sci Tech Res 2018; 8(5):10p.. doi:10.26717/BJSTR.2018.08.001706
33. Carlson NE, Roach RB Jr. Platelet-rich plasma: clinical applications in dentistry. J Am Dent Assoc. 2002 0ct;133(10):1383-6

34. Tözüm TF,Demiralp B. Platelet-rich plasma: a promising innovation in dentistry. JCanDent Assoc. 2003 Nov;69(10):664

35. Shashikiran ND, Reddy VV, Yavagal CM, Zakirulla M. Applications of plateletrich plasma (PRP) in contemporary pediatric dentistry. J Clin Pediatr Dent. 2006 Summer;30(4):283-6.

36. Tamimi FM, MontalvoS, Tresguerres I,Blanco JerezL. A comparative study of 2 methods for obtaining platelet-rich plasma. J Oral Maxillofac Surg. 2007 Jun:65(6):1084-93

37. Nikolidakis D, Jansen JA. The biology of platelet-rich plasma and its application in oral surgery: literature review. Tissue Eng PartB Rev. 2008 Sep;14(3):249-58. doi:10.1089/ten.teb.2008.0062.

38. Plachokova AS, Nikolidakis D, Mulder J, Jansen JA, Creugers NH. Effect of platelet-rich plasma on bone regeneration in dentistry: a systematic review. Clin Oral Implants Res. 2008 Jun;19(6):539-45. doi:10.1111/j.1600 0501.2008.01525.x.

39. Arora NS, Ramanayake T, Ren YF, Romanos GE. Platelet-rich plasma: a literature review. Implant Dent. 2009 Aug;18(4):303-10. doi: 10.1097/ ID.0b013e31819e8ec6.

40. Kaur P,Puneet, Dahiya V. Platelet-rich plasma: a novel bioengineering concept Trends Biomater Artif Organs. 2011; 25:86-90.

41. Simonpieri A, Del Corso M, Vervelle A, Jimbo R, Inchingolo F, Sammartino G, et al. Current knowledge and perspectives for the use of platelet-rich plasma (PRP) and platelet-rich fibrin (PRF) in oral and maxillofacial surgery part2: Bone graft, implant and reconstructive surgery. Curr Pharm Biotechnol. 2012 Jun;13(7):1231-56.

42. Albanese A, Licata ME, Polizzi B, Campisi G. Platelet-rich plasma(PRP) in dental and oral surgery: from the wound healing to bone regeneration. Immun Ageing 2013 Jun 13;10(1):23. doi: 10.1186/1742-4933-10-23.

43. Roffi A, Filardo G, KonE, Marcacci M. Does PRP enhance bone integration with grafts, graft substitutes, or implants? A systematic review. BMC Musculoskelet Disord. 2013 Nov 21;14:330. doi: 10.1186/1471-2474-14-330.

44. Zollino I,Candotto V, Silvestre FX, Lauritano D. Efficacy of platelet-rich plasma in oral surgery and medicine: an overview. Ann Oral Maxillofac Surg 2014;2:5.

45. Priya N. Platelet rich plasma. IOSR J Dental Med Sci 2014; 13:41-3.

46. Naag S, Savirmath A, Kalakonda BB, Uppada UK, Kamisetty S, PriyadarshiniE. Platelet concentrates: Bioengineering dentistry's regenerative dreams. J Dent Res Re2015;2: 86-90.

47. Rodella LF, Bonazza V.Platelet preparations in dentistry: How? Why? Where? When? World J Stomatol. 2015; 4:39-55.

48. Vineet RV.Platelet rich plasma: The new paradigm in dentistry. J Dent Oral Care 2016;2:1-2.

49. Bansal S, Garg A, Khurana R, Chhabra P.Platelet-rich fibrin or platelet-rich plasma - Which one is better? An opinion. Indian JDent Sci 2017; 9: S49-52.

50. Huang Y, Bornstein MM, Lambrichts I, Yu HY, Politis C, Jacobs R. Platelet-rich plasma for regeneration of neural feedback pathways around dental implants: a concise review and outlook on future possibilities. Int J Oral Sci. 2017 Mar;9(1):1-9. doi: 101038/ijos.2017.1.

51. Singh V, Singh R, Singh G. Platelet rich plasma - a new revolution in medicine. J Anatom Soc India 2017;66:S28-S30.

52. Boutros E, Atik A. Effect of the use of platelets: Rich plasma (PRP) on periapical bone repair following Apicectomy on a sample of patients from the middle area in Syria. Inter J Appl Dental Sci 2018;4:143-6. 
53. Murray PE, Minireview of the clinical efficacy of platelet-rich plasma, plateletrich fibrin and blood-clot revascularization for the regeneration of immature permanent teeth. World J Stomatol 2018; 6:1-5.

54. Alves R, GrimaltR. A Review of platelet-rich plasma: history, biology, mechanism of action, and classification. Skin Appendage Disord. 2018 Jan;4(1):18-24. doi: 10.1159/000477353.

55. Kobayashi E, Fujioka-Kobayashi M, Sculean A, Chappuis V,Buser D, Schaller $B$, etal. Effects of platelet rich plasma (PRP) on human gingival fibroblast, osteoblast and periodontal ligament cell behaviour. BMC Oral Health. $2017 \mathrm{Jun}$ 2;17(1):91. doi: 10.1186/s12903-017-0381-6

56. Otero L, Carrillo N, Calvo-Guirado JL, Villamil J, Delgado-RuízRA. Osteogenic potential of platelet-rich plasma in dental stem-cell cultures. Br J Oral Maxillofac Surg.2017 Sep;55(7):697-702. doi:10.1016/j.bjoms.2017.05.005.

57. Nguyen PA, Pham TAV. Effects of platelet-rich plasma on human gingival fibroblast proliferation and migration in vitro. J Appl Oral Sci. 2018 Jul 10;26:e20180077. doi: 10.1590/1678-7757-2018-0077

58. Pessoa RS, Oliveira SR, Menezes HH, de Magalhaes D. Effects of plateletrich plasma on healing of alveolar socket: split-mouth histological and histometric evaluation in Cebus apella monkeys. Indian J Dent Res. 2009 Oct-Dec;20(4):442-7. doi:10.4103/0970-9290.59448

59. Bassi AP,Carvalho PS. Repair of bone cavities in dog's mandible filled with inorganic bovine bone and bioactive glass associated with platelet rich plasma. BrazDent J. 2011;22(1):14-20.

60. Zhu X, Zhang C, Huang GT, Cheung GS, Dissanayaka WL, Zhu W. Transplantation of dental pulp stem cells and platelet-rich plasma for pulp regeneration. J Endod. 2012 Dec;38(12):1604-9. doi: 10.1016/j.joen.2012.09.001.

61. Zhu W, Zhu X, Huang GT, Cheung GS, Dissanayaka WL, Zhang C. Regeneration of dental pulp tissue in immature teeth with apical periodontitis using plateletrich plasma and dental pulp cells. Int Endod J.20130ct;46(10):962-70. doi: 10.1111/iej.12087.

62. Zhang $L, X i e Y H, L i n B R$. Effects of washed platelets vs platelet-rich plasma on the proliferation and mineralization of rat dental pulp cells. Genet Mol Res. 2015 Aug 14;14(3):9486-96. doi: 10.4238/2015.August.14.12

63. Toro LF, de Mello-Neto JM, Santos FFVD, Ferreira LC, Statkievicz C, Cintra LTÂ, et al. Application of autologous platelet-rich plasma on toothextraction site prevents occurence of medication-related osteonecrosis of the jaws in rats. Sci Rep. 2019 Jan 10;9(1):22. doi: 10.1038/s41598-018-37063-y.

64. Rutkowski JL, Johnson DA, Radio NM, Fennell JW. Platelet rich plasma to facilitate wound healing following tooth extraction. J Oral Implantol. 2010;36(1):11-23. doi: 10.1563/AAID-J0I-09-00063

65. Ergun G, EgilmezF,Cekic-Nagas I, Rana Karaca I,Bozkaya S. Effect of plateletrich plasma on the outcome of early loaded dental implants: A 3-year followup study. J Oral Implantol 2013;39:256-63.
66. Ocampo BRY,González MGM. Treatment of localized aggressive periodontitis with platelet-rich plasma and bone allograft. Clinical case report. Rev Odontol Mexicana 2015; 19: 106-13.

67. LiouEJ. The development of submucosal injection of platelet rich plasma for accelerating orthodontic tooth movement and preserving pressure side alveolar bone. APOS Trends Orthod 2016; 6:5-11.

68. Wen J,LiHT,LiSH,LiX, Duan JM. Investigation of modified platelet-rich plasma (mPRP) in promoting the proliferation and differentiation of dental pulpstem cells from deciduous teeth. Braz J Med Biol Res. 2016 Sep 1;49(10):e5373.doi: 10.1590/1414-431X20165373.

69. Isaia L, Isaia B, IsaiaF, Traini T. The effects of the combined use of platelet-rich plasma and xenograft on alveolar socket healing. Biomed J Sci Tech Res 2018, 3:1.

70. Vance GS, Greenwell H, Miller RL, Hill M, Johnston H, Scheetz.JP.Comparison of an allograft in an experimental putty carrier and a bovine-derived xenograft used in ridge preservation: a clinical and histologic study in humans. Int J Oral Maxillofac Implants. 2004 Jul-Aug;19(4):491-7.

71. Alagl A, Bedi S, Hassan K, AlHumaid J. Use of platelet-rich plasma for regeneration in non-vital immature permanent teeth: Clinical and cone-beam computed tomography evaluation. J IntMed Res. 2017 Apr;45(2):583-593. doi: 10.1177/0300060517692935.

72. Gopinath A, Ravikanth A, Kadiyala KK, Thota KM, Manne P,Babu MS. Effect of platelet rich plasma on stability of dental implants: A prospective comparative clinical study. JNTRUniv Health Sci 2017; 6: 107-13.

73. Jalaluddin M, Mahesh J,Mahesh R, Jayanti I,Faizuddin M, Kripal K, etal. Effectiveness of platelet rich plasma and bone graft in the treatment of intrabony defects: a clinico-radiographic study. Open Dent J.2018 Feb 12;12:133-154. doi: 10.2174/1874210601812010133.

74. FDA, 2018. Guidance for Industry Regulation of Human Cells, Tissues, and Cellular and Tissue-Based Products (HCT/Ps) CFR-Code of Federal Regulations Title 21. cited April 12019 -. Available from: https:// www.accessdatafda.gov/scripts/cdrh/cfdocs/cfcfr/cfrsearch. cfm?CFRPart01271\&showFR01

75. Beitzel K, Allen D, Apostolakos J, Russell RP, McCarthy MB, Gallo GJ etal. US definitions, current use, and FDA stance on use of plateletrich plasma in sports medicine. J Knee Surg. 2015 Feb;28(1):29-34. doi:10.1055/s-0034-1390030.

76. CPSA (College of Physicians and Surgeons of Alberta). Approved June 2018.p.15(2018). Available from:http://www.cpsa.ca/wp-content/uploads/2018/09/ PRP-guidelines-June-2018.pdf.

\section{Nelson Durán}

(Corresponding address)

Laboratory of Urogenital Carcinogenesis and Immunotherapy, Depart-

ment of Structural and Functional Biology

University of Campinas (UNICAMP)

Av. Bertrand Russel, s/n., CP 13083-865, Campinas, SP, Brazil.

Date submitted: 2019 Aug 01

E-mail: nelsonduran1942@gmail.com / nduran@unicamp.br. 